\title{
Silicon-assisted O-heterocyclic synthesis: mild and efficient one-pot syntheses of $(E)$-3-benzylideneflavanones, coumarin-3-carbonitriles / carboxamides, and benzannulated spiropyran derivatives
}

\author{
Tarek A. Salama, ${ }^{* a}$ Mohamed A. Ismail, ${ }^{\text {a,b }}$ Abdel-Galil M. Khalil, ${ }^{a}$ and Saad S. Elmorsy ${ }^{a}$ \\ ${ }^{a}$ Chemistry Department, Faculty of Science, Mansoura University, 35516-Mansoura, Egypt \\ ${ }^{b}$ Chemistry Department, College of Science, King Faisal University, P.O. Box. 380, \\ Hofuf 31982, Saudi Arabia \\ E-mail: tasalama@yahoo.com
}

\begin{abstract}
A new general and efficient method for the one-pot synthesis of $(E)$-benzylideneflavanones, dibenzospiropyrans and coumarin-3-carbonitriles/carboxamides is achieved through tandem aldol-cyclocondensation of $o$-hydroxyaryl carbonyl compounds with aryl aldehydes or enolisable ketones or through Knoevenagel reaction by the aid of $\mathrm{SiCl}_{4} / \mathrm{EtOH}$ at ambient temperature.
\end{abstract}

Keywords: O-Heterocycles, tetrachlorosilane-ethanol, one-pot synthesis, cyclocondensation

\section{Introduction}

3-Benzylideneflavanones, termed as flavindogenides, are important building blocks in synthesis and their skeleton is common in some natural products. ${ }^{1}$ For example, they are precursors of spiroheterocycles, ${ }^{2}$ as well as biologically important flavones. ${ }^{3}$ Moreover, a number of 3-benzylideneflavanones possess pharmacological activity such as anti-inflammatory, antioxidant, analgesic and anti-bacterial properties. ${ }^{4}$ 3-Benzylideneflavanones are commonly synthesized either by acid or base catalyzed condensation of flavanones with aromatic aldehydes. ${ }^{5}$ They have also been isolated as co-products during the preparation of flavanones through the acid or base catalyzed condensation of aromatic aldehydes and substituted $o$-hydroxyacetophenones. ${ }^{6}$ Chawla et $a{ }^{7} .^{7}$ reported the synthesis of 3-benzylideneflavanones by condensing 2-hydroxyacetophenones with aromatic aldehydes in aqueous alkaline medium, along with corresponding chalcones. According to these authors benzylideneflavanones were accessible only by a low-yielding circuitous route. To the best of our knowledge, only one protocol claimed a one-pot synthesis of (E)-3-benzylideneflavanones through base catalyzed condensation of aromatic aldehydes with $o$-hydroxyacetophenones over a relatively long time 
(i.e. the reaction mixture had to be kept under stoppered condition for four days with occasional shaking). 4,8

On the other hand, coumarin-3-carbonitriles are important compounds as they are required for the synthesis of methine dyes, ${ }^{9} 3$-carboxycoumarins that are used for the synthesis of cephalosporins, ${ }^{10}$ modified penicillins ${ }^{11}$ and oxygen-bridged tetrahydropyridones. ${ }^{12}$ The amides obtained from 3-cyanocoumarins exhibit specific inhibitors of $\alpha$-chemotripsin ${ }^{13}$ and leukocyte elastase. ${ }^{14}$ Coumarin-3-carbonitriles have been synthesized by reaction of salicylic aldehydes with malononitrile or ethylcyanoacetate, in the presence of bases ${ }^{15}$ such as pyridine, ${ }^{15 \mathrm{c}}$ pyridinepiperidine, ${ }^{15 \mathrm{~d}}$ triethylamine, ${ }^{15 \mathrm{e}}$ or under phase-transfer catalysis. ${ }^{16}$ However, in most of reported procedures, coumarin-3-carbonitriles are obtained along with 2-imino-2H-benzopyran-3carbonitriles which are hydrolyzed in $\mathrm{HCl} / \mathrm{MeOH}$ to give the desired products. ${ }^{15 \mathrm{e}}$ Greener approaches for Knoevenagel synthesis of coumarin-3-carbonitriles using ionic liquids as well as inorganic solid supports or basic catalysts in aqueous media have also been developed. ${ }^{16-18}$ Nevertheless, some of these protocols are disadvantageous in terms of the limited availability of catalyst $\left(\mathrm{ZrCl}_{4} /[\mathrm{bmim}] \mathrm{BF}_{4}\right),{ }^{16}$ the large quantities of solid support used (alumina, $0.3 \mathrm{~g} / 1 \mathrm{mmol}$ of hydroxyaldehyde), ${ }^{17}$ or the long reaction times under reflux conditions (KSF, $160{ }^{\circ} \mathrm{C} / 24 \mathrm{~h}$, solvent-free. KSF, $100{ }^{\circ} \mathrm{C} / 24 \mathrm{~h}, \mathrm{H}_{2} \mathrm{O},{ }^{17}$ cat. $\mathrm{NaOH}, 100{ }^{\circ} \mathrm{C} / 24 \mathrm{~h}, \mathrm{H}_{2} \mathrm{O}^{18}$ ). The development of novel synthetic strategies for $\mathrm{O}$-heterocycles which have advantages with respect to using less expensive and readily available reagents, mild reaction conditions, cleaner reactions, and simple isolation of the product are of interest. Within this context and in conjunction with our interest ${ }^{19}$ in exploring the utility of in situ reagents based on tetrachlorosilane (TCS, $\left.\mathrm{SiCl}_{4}\right)^{20}$ in organic synthesis, we report herein the use of $\mathrm{SiCl}_{4}$ as an efficient dehydrating agent in achieving cyclocondensation as well as Knoevenagel reactions resulting in the formation of various $\mathrm{O}$ heterocycles. The process involves sequential reaction of the $o$-hydroxycarbonyl compounds with aromatic aldehydes, malononitrile or cyanoacetamide in the presence of the inexpensive and readily available $\mathrm{SiCl}_{4} / \mathrm{EtOH}$ mixture to furnish (E)-benzylideneflavanones, coumarin-3carbonitriles/carboxamides, respectively at room temperature. Under these very mild conditions, the reaction was explored to synthesize benzannulated spiropyrans quantitatively via cyclocondensation of salicylaldehyde with cycloalkanones.

\section{Results and Discussion}

A convenient one-pot synthesis of (E)-3-benzylideneflavanones through the reaction of $o$-hydroxyacetophenone with aromatic aldehydes in the presence of tetrachlorosilane in absolute ethanol at ambient temperature has been achieved. Stirring a mixture of $o$-hydroxyacetophenone ( 1 equiv.) and aromatic aldehyde (2.5 equiv.) in the presence of tetrachlorosilane ( 6 equiv.) in absolute ethanol as a solvent at ambient temperature led to the formation of (E)-3benzylideneflavanones 3a-d in good yield (Scheme 1, Table 1). Although only two moles of aldehydes are needed for this reaction, the best results were obtained through the use of 2.5 
equivalents of aldehydes. This observation seemed reasonable as the formation of flavindogenides is a reaction which is achieved under equilibrating conditions when starting with $o$-hydroxyacetophenone and aldehydes. ${ }^{8}$ Thus, higher concentration of aromatic aldehyde would displace the final equilibrium to the forward direction. It is significant that the yields of benzylideneflavanones in the present procedure are strongly dependent upon the amount and the manner of addition of tetrachlorosilane to the reactants. The best yields were obtained by using six equivalents $(3 \times 2$ equiv. $)$ of tetrachlorosilane added during the reaction period, otherwise many side products were obtained.<smiles>[R]c1cc(/C=C2\C(=O)c3ccccc3OC2c2cc([R])c([R])c([R])c2/C=C/C(=O)O)cc([R])c1[R]</smiles>

2a, 3a: $R^{1}=R^{3}=H, R^{2}=C l$

2b, 3b: $R^{1}=R^{3}=H, R^{2}=B r$

2c, 3c: $R^{1}=R^{3}=H, R^{2}=M e$

2d, 3d: $R^{1}=R^{3}=H, R^{2}=O M e$

2e: $R^{1}=R^{3}=R^{3}=O M e$

\section{Scheme 1.}

Table 1. One-pot synthesis of $(E)$-3-benzylideneflavanones utilizing TCS-EtOH

\begin{tabular}{ccccccc}
\hline Entry & $\begin{array}{c}\text { Substrate } \\
\mathbf{2}\end{array}$ & $\begin{array}{c}\text { Time } \\
\text { (h) }\end{array}$ & Product & $\begin{array}{c}\text { Yield } \\
(\%)^{\mathrm{a}}\end{array}$ & $\begin{array}{c}\mathrm{mp} \\
\left({ }^{\circ} \mathrm{C}\right)\end{array}$ & $\begin{array}{c}\text { Lit. mp } \\
\left({ }^{\circ} \mathrm{C}\right)\end{array}$ \\
\hline 1 & $\mathbf{2 a}$ & 14 & $\mathbf{3 a}$ & 74 & $225-7$ & $222-4^{8}$ \\
2 & $\mathbf{2 b}$ & 17 & $\mathbf{3 b}$ & 69 & $243-5$ & $245^{30}$ \\
3 & $\mathbf{2 c}$ & 16 & $\mathbf{3 c}$ & 82 & 124 & $126-7^{34}$ \\
4 & $\mathbf{2 d}$ & 18 & $\mathbf{3 d}$ & 71 & 136 & $136^{8}$ \\
5 & $\mathbf{2 e}$ & 13 & $\mathbf{4}$ & 87 & 175 & $174^{22}$ \\
\hline
\end{tabular}

${ }^{\mathrm{a}}$ Isolated yield

The results summarized in Table 1 showed that the formation of 3-benzylideneflavanones proved to be general and quite efficient for aryl aldehydes and tolerated a variety of functional groups on the phenyl ring regardless of whether electron-donating or electron-withdrawing in character. Thus, chloro, bromo, methyl, and methoxy-containing aromatic aldehydes reacted smoothly at room temperature to give the respective 3-benzylideneflavanones in good yields. The identification of 3-benzylideneflavanones was carried out by spectroscopic analyses as well as by comparing their properties to those reported. The stereochemistry of the 3-benzylidene- 
flavanone derivatives was unambiguously determined from the ${ }^{1} \mathrm{H}$ NMR spectra which showed that the product 3 exists only in the $E$ form. ${ }^{5}$ The $E$ isomers are crystalline solids and an examination of their purity using thin layer chromatography showed no trace of a second isomer. For example, the ${ }^{1} \mathrm{H}$ NMR spectra of the $E$-flavindogenides $\mathbf{3 a}$ and $\mathbf{3 c}$ obtained by the present method showed two broadened singlets at $\delta 7.96,8.05$ and $6.43,6.61 \mathrm{ppm}$, respectively. The two singlets are due to the proton at $\beta$-carbon (vinylic proton) and the proton at $\mathrm{C}-2(\mathrm{H}-2)$, respectively. The observed broadening of the signal is attributed to a small long range allylic coupling $^{21}$ between the two protons or most likely due to hindered rotations of the bulky aromatic groups. An absorption, for example, at $\delta 8.05$ (for $\mathrm{H} \beta$ in 3c) is much lower than expected for an ordinary vinyl proton and indicates the $E$ configuration of the flavindogenides $3 \mathbf{a}$ and $\mathbf{3 c}$ in which the vinylic proton lies well in the deshielding zone of the carbonyl group. In addition, the H-5 protons of 3a and $\mathbf{3 c}$ absorb at a lower field $(\delta=7.86-7.90)$ than the other aromatic protons. The shift of the aromatic $\mathrm{H}-5$ proton downfield arises from the deshielding effect of the carbonyl group and is characteristic of flavanone and flavone systems. Mass spectral (MS) measurements of 3a and $\mathbf{3 d}$ displayed their corresponding molecular ions $\left(\mathbf{M}^{+}\right) \mathrm{m} / z 380$ and 372 , respectively. However, the spectral data of the product from the reaction of $o$-hydroxyacetophenone with $3^{\prime}, 4^{\prime}, 5^{\prime}$-trimethoxybenzaldehyde under the same reaction conditions (entry 5) and as judged by the melting point, ${ }^{22}$ showed it to be $3^{\prime}, 4^{\prime}, 5^{\prime}$-trimethoxyflavone (4) instead of the anticipated benzylideneflavanone. The formation of compound $\mathbf{4}$ is the result of condensation of only one mole of the aldehyde $2 \mathbf{e}$ with one mole of $o$-hydroxyacetophenone which may be attributed to the steric factor and/or to the lower reactivity of $\mathbf{2 e}$ attributed to the three electrondonating groups. ${ }^{3 \mathrm{~b}}$ Such flavones were synthesized in the literature through oxidative cyclization of the corresponding $o$-hydroxychalcones. ${ }^{23}$

A reasonable pathway for the formation of 3-benzylideneflavanones $\mathbf{3}$ may agree with that depicted in Scheme 3. $\mathrm{SiCl}_{4}$ may react with ethanol to form the reagent system $\mathrm{A}^{24}$ which may form siloxy species $\mathbf{B}$ as well silyl enolate $\mathbf{C}$ via its reaction with aldehydes and $o$-hydroxyacetophenone, respectively. Attack of $\mathbf{C}$ on $\mathbf{B}$ in an aldol-type condensation ${ }^{25}$ followed by cyclisation would produce $\mathbf{D}$ which reacts with another mole of aldehyde to give the desired product after aqueous work-up. 


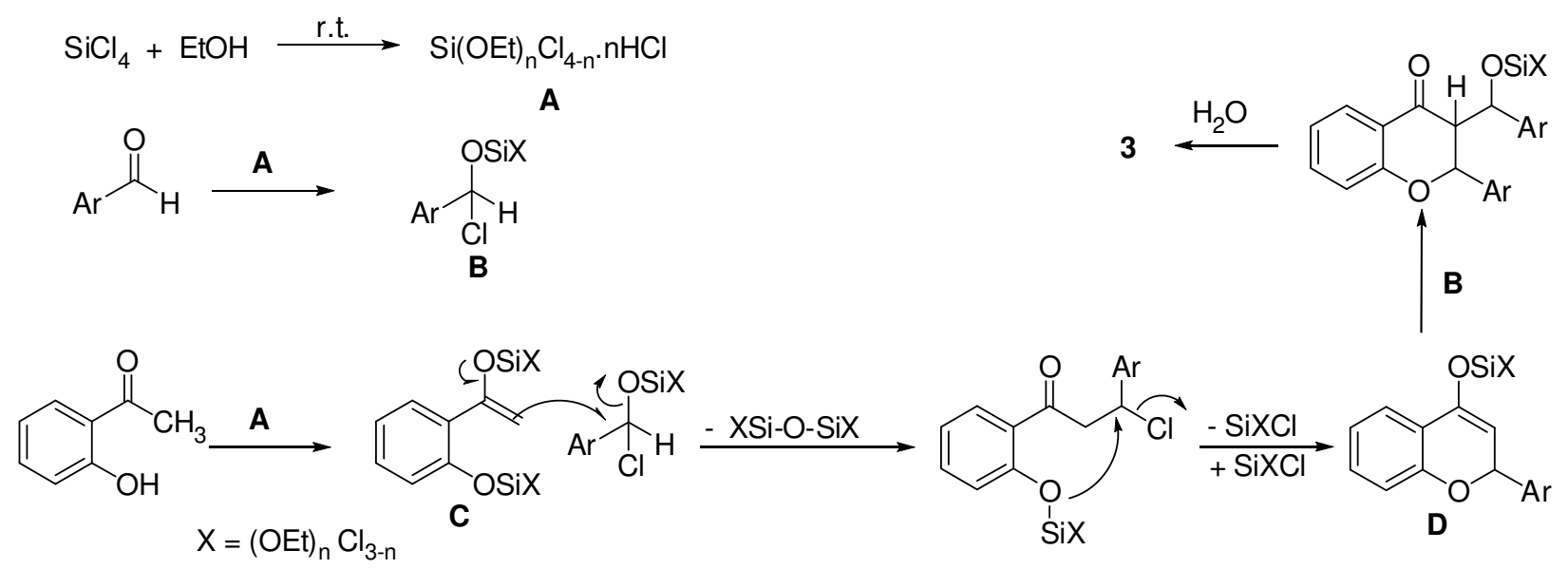

\section{Scheme 2}

Following our interest concerning the use of tetrachlorosilane as dehydrating agent in heterocyclic synthesis, we investigated the Knoevenagel synthesis of coumarin derivatives in the presence of $\mathrm{SiCl}_{4} / \mathrm{EtOH}$. To study this process, we examined the reaction of salicylaldehyde (10 $\mathrm{mmol})$ with malononitrile $(10 \mathrm{mmol})$ in the presence of two equivalents of tetrachlorosilane $(2.4$ $\mathrm{mmol})$ in ethanol $(15 \mathrm{~mL})$ at room temperature. We observed that tetrachlorosilane promoted the process affording the coumarin $\mathbf{6 a}$ within $15 \mathrm{~min}$. Various $o$-hydroxycarbonyl compounds were reacted under similar conditions, allowing the easy synthesis of coumarin-3-carbonitriles $\mathbf{6}$ in quantitative yield without chromatography (Scheme 2, Table 2). With respect to reports that utilize $\mathrm{SiCl}_{4} / \mathrm{EtOH}$ as a dehydrating ${ }^{25}$ and hydrolyzing agent, ${ }^{26}$ the reaction path may include steps involving a typical Knoevenagel condensation of $o$-hydroxycarbonyl compound and malononitrile or cyanoacetamide. Hydrolysis of a cyano group gives the intermediate $\mathbf{E}$ which furnishes coumarin derivatives $\mathbf{6}$ after an aqueous work-up. All products melting points and spectral analyses were comparable with those of the reported compounds. ${ }^{18,31}$<smiles>[R]CC[N+]#[C-]</smiles>

$1 a-d$
$5 a, b$

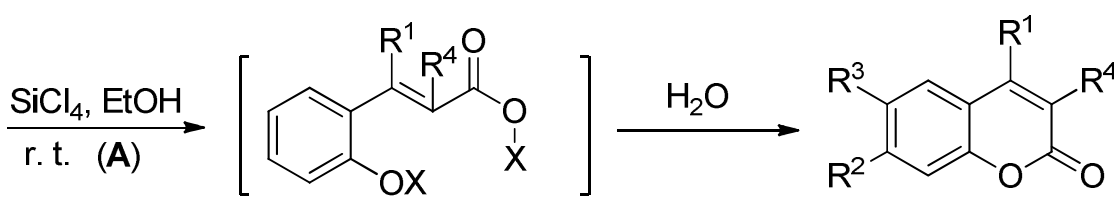

$\mathrm{E}$

$6 a-e$

$$
\mathrm{X}=\mathrm{Si}(\mathrm{OEt})_{n} \mathrm{Cl}_{3-n}
$$

\section{Scheme 3}


Table 2. One-pot synthesis of coumarin-3-carbonitriles/carboxyamides utilizing TCS-EtOH

\begin{tabular}{cccccccccc}
\hline Entry & $\mathrm{R}^{1}$ & $\mathrm{R}^{2}$ & $\mathrm{R}^{3}$ & $\mathrm{R}^{4}$ & $\begin{array}{c}\text { Time } \\
(\mathrm{h})\end{array}$ & $\mathbf{6}$ & $\begin{array}{c}\text { Yield } \\
(\%)\end{array}$ & $\begin{array}{c}\mathrm{mp} \\
\left({ }^{\circ} \mathrm{C}\right)\end{array}$ & $\begin{array}{c}\text { Lit. } \mathrm{mp} \\
\left({ }^{\circ} \mathrm{C}\right)\end{array}$ \\
\hline 1 & $\mathrm{H}$ & $\mathrm{H}$ & $\mathrm{H}$ & $\mathrm{CN}$ & 0.25 & $\mathbf{6 a}$ & 96 & 183 & $179-81^{18}$ \\
2 & $\mathrm{Me}$ & $\mathrm{H}$ & $\mathrm{H}$ & $\mathrm{CN}$ & 0.75 & $\mathbf{6 b}$ & 92 & 191 & $190^{18}$ \\
3 & $\mathrm{Me}$ & $\mathrm{H}$ & $\mathrm{OH}$ & $\mathrm{CN}$ & 3 & $\mathbf{6 c}$ & 86 & 273 & $274^{31 \mathrm{a}}$ \\
4 & $\mathrm{H}$ & $(-\mathrm{CH}=\mathrm{CH}-)_{2}$ & $\mathrm{CN}$ & 2 & $\mathbf{6 d}$ & 93 & 301 & $>300^{31 \mathrm{~b}}$ \\
5 & $\mathrm{H}$ & $\mathrm{H}$ & $\mathrm{H}$ & $\mathrm{CONH}_{2}$ & 3 & $\mathbf{6 e}$ & 85 & 269 & $270^{31 \mathrm{c}}$ \\
\hline
\end{tabular}

${ }^{\mathrm{a}}$ Isolated yield.

Spiroketals are crucial substructures in a wide variety of natural compounds of diverse origins $^{27 \mathrm{a}}$ and owing to their broad spectrum of biological activities, ${ }^{27 \mathrm{~b}}$ these moieties have therefore attracted considerable synthetic interest. ${ }^{28}$ The main approach for the synthesis of spiroketal units involves elaboration of a key acyclic keto-diol or its equivalent via intermolecular $\mathrm{C}-\mathrm{C}$ bond formations followed by an intramolecular acid-catalyzed dehydrative ketalization. $^{29}$ Exploring the utility of the dual function of tetrachlorosilane/ethanol as a dehydrating agent and inducing aldol condensation in heterocyclic synthesis, we have investigated the reaction of salicylaldehyde with some bis-active methylene containing ketones such as cycloalkanones and dibenzalacetone envisaging that the reaction may proceed to yield the bis-chalcones, keto-diol type products which then, may undergo an intramolecular dehydrative ketalization under the reaction conditions yielding spiroketal derivatives. Thus, stirring a mixture of salicylaldehyde $(20 \mathrm{mmol})$ and cyclohexanone $(10 \mathrm{mmol})$ in ethanol $(20$ $\mathrm{mL}$ ) for $2 \mathrm{~h}$ at room temperature in the presence of tetrachlorosilane (2 equiv.) gave the dibenzospiroketal derivatives $\mathbf{8 b}$ in quantitative yield after an aqueous work up. The reaction was successfully extended to substituted cyclohexanones such as 4-methylcyclohexanone to give the corresponding dibenzospiropyran derivative in good yield. Under similar conditions, the reaction has proved to be quite efficient with either lower or higher members of cycloalkanones. Thus, the reaction with cyclopentanone, cycloheptanone and cyclooctanone yielded the respective dibenzospiropyran derivatives. The reaction of salicylaldehyde with acyclic active methylene ketones such as 1,3-diphenylacetone yielded products $\mathbf{1 0}$ and $\mathbf{9}$ as a result of condensation of one mole of 1,3-diphenylacetone with either one or two moles of salicylaldehyde, respectively. 


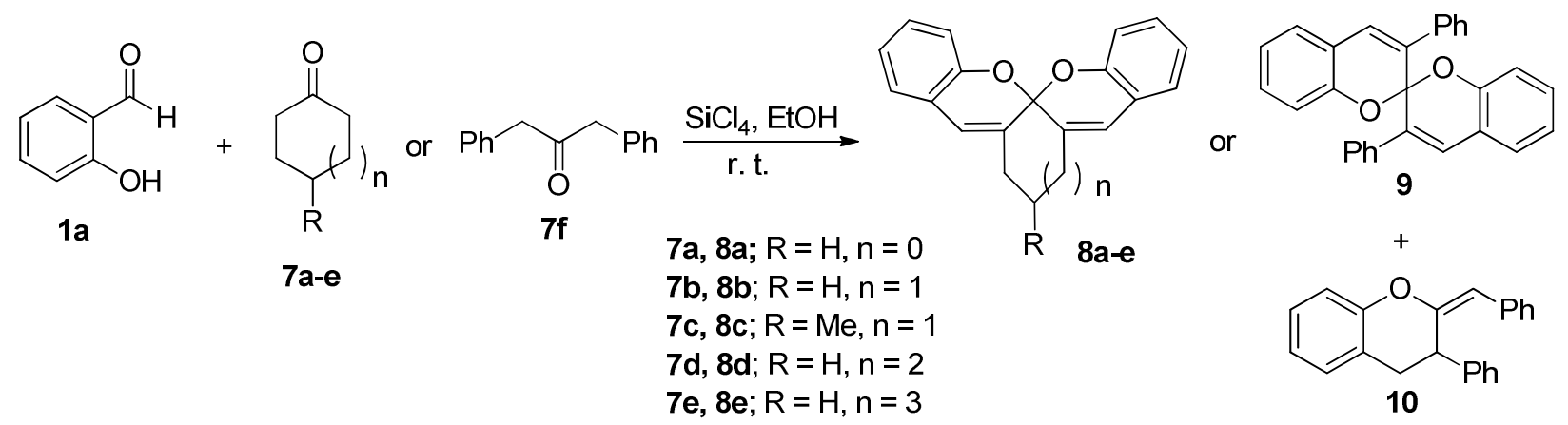

\section{Scheme 4.}

Table 3. One-pot synthesis of dibenzospiropyrans utilizing $\mathrm{SiCl}_{4} / \mathrm{EtOH}$

\begin{tabular}{|c|c|c|c|c|c|c|}
\hline Entry & $\begin{array}{c}\text { Substrate } \\
\mathbf{7} \\
\end{array}$ & $\begin{array}{c}\text { Time } \\
\text { (h) }\end{array}$ & Product & $\begin{array}{l}\text { Yield } \\
(\%)^{\mathrm{a}}\end{array}$ & $\mathrm{mp}\left({ }^{\circ} \mathrm{C}\right)$ & $\begin{array}{c}\text { Lit. mp } \\
\left({ }^{\circ} \mathrm{C}\right)\end{array}$ \\
\hline 1 & $7 a$ & 4 & $8 \mathbf{a}$ & 92 & $213-5$ & $215^{32}$ \\
\hline 2 & $7 b$ & 2 & $8 b$ & 94 & 156 & $156^{32}$ \\
\hline 3 & $7 c$ & 3 & $8 c$ & 91 & 138 & $139-40^{32}$ \\
\hline 5 & $7 e$ & 4 & $8 d$ & 95 & $202-4$ & $207-8^{35}$ \\
\hline 6 & $7 f$ & 3 & $8 e$ & 93 & 187 & \\
\hline \multirow[b]{2}{*}{7} & \multirow[b]{2}{*}{$7 g$} & \multirow[b]{2}{*}{6} & 9 & 38 & $196-7$ & $197^{33}$ \\
\hline & & & 10 & 45 & $113-5$ & $115^{33}$ \\
\hline
\end{tabular}

${ }^{\mathrm{a}}$ Isolated yield.

All isolated compounds are solids and readily crystallized from either ethanol or acetone. The structure elucidation of dibenzospiropyrans $\mathbf{8}$ was assigned on the basis of both elemental and spectral analyses. In the IR spectra, no hydroxyl group $(\mathrm{OH})$ stretching frequency was observed but, rather, all products displayed a characteristic ether-linkage $(\mathrm{C}-\mathrm{O})$ stretching band at $v_{\max }$ 1227-1213 $\mathrm{cm}^{-1}$, supporting the cyclization step. Mass spectral measurements (MS) for $\mathbf{8 b}$ displayed the $m / z 288$ peak corresponding in mass to the molecular ion $\left(\mathbf{M}^{+}\right)$. The ${ }^{1} \mathrm{H}-\mathrm{NMR}$ spectra of dibenzospiropyrans contain several notable features: no absorption bands for the hydroxyl group protons, the spectra were in agreement with the depicted structures, and the resemblance of the aromatic and olefinic protons as well as carbon skeleton system in dibenzospiropyran derivatives. The formation of $\mathbf{8}$ may proceed through an intramolecular dehydrative ketalization of the formed bis-chalcone intermediates. Similar transformation of keto-diols to spiroketals under acid catalysis is well documented. ${ }^{29}$ 


\section{Conclusions}

In summary, we have developed a simple, mild and efficient protocol for the one-pot syntheses of various O-heterocycles from readily available substrates, employing the cheap tetrachlorosilane-ethanol mixture at ambient temperature. (E)-3-Benzylideneflavanones as well as dibenzospiropyran derivatives were prepared through tandem aldol-cyclocondensation / ketalization reaction sequence. Knoevenagel synthesis of coumarin-3-carbonitriles / carboxamides has been developed under the same reaction conditions. This protocol has a few noteworthy features: Good yields can be obtained, great operational simplicity at ambient temperature, and applicability of this protocol for various substrates. Exploring this protocol for preparation of biologically important spiroketals is on-going project in our laboratory.

\section{Experimental Section}

General. Melting points were determined using a Griffin melting point apparatus. The IR spectra were recorded with Mattson FTIR spectrometer 5000. Absorption maxima were measured in $\mathrm{cm}^{-1}$. The ${ }^{1} \mathrm{H}$ NMR and ${ }^{13} \mathrm{C}$ NMR spectra were recorded with Bruker 200, 300, $400 \mathrm{MHz}$ spectrometer instruments in $\mathrm{CDCl}_{3}$. The chemical shifts $(\delta)$ were measured in ppm and with the solvents as references (For $\mathrm{CDCl}_{3},{ }^{1} \mathrm{H}: \delta=7.26 \mathrm{ppm},{ }^{13} \mathrm{C}: \delta=77.0 \mathrm{ppm}$ ). MS spectra were recorded on GC-MS QP-1000 EX Shimadzu mass spectrometer. Column chromatography was performed on silica gel (100-200 or 200-300 mesh) using petroleum ether and ethyl acetate as eluent. Thin layer chromatography (TLC) was performed on Merck silica gel $\mathrm{GF}_{254}$ plates and visualized by UV-light $(254 \mathrm{~nm})$. Tetrachlorosilane was used as obtained from commercial sources. Ethanol was purified and dried according to standard procedures.

General procedure for the synthesis of 3-benzylideneflavanones (3). To a cold solution of 2'hydroxyacetophenone $(5 \mathrm{mmol})$ and aldehyde $2(12.5 \mathrm{mmol})$ in absolute ethanol $(20 \mathrm{~mL})$ was added $\mathrm{SiCl}_{4}(10 \mathrm{mmol})$ and the mixture was allowed to stir for $2 \mathrm{~h}$. An additional amount of $\mathrm{SiCl}_{4}(10 \mathrm{mmol})$ was added and the reaction mixture was kept stirring for $4 \mathrm{~h}$. Then further $\mathrm{SiCl}_{4}$ (10 mmol) finally was added and the reaction was stirred at ambient temperature for the total recorded time. After completion (the reaction was monitored by TLC), the mixture was poured into ice-water $(100 \mathrm{~mL})$, the formed precipitate was filtered, dried and recrystalized from ethanol or acetone to give pure $\mathbf{3 a}, \mathbf{b}, \mathbf{d}$ or $\mathbf{3 c}$, respectively. The $(E)$-3-benzylideneflavanones $\mathbf{3}^{8,30,34}$ and the flavone $4^{22}$ are known compounds and all spectroscopic data were in agreement with literature.

(E)-3-(4-Chlorobenzylidene)-2-(4-chlorophenyl)chroman-4-one (3a). Colorless solid, mp 225-227 ${ }^{\circ} \mathrm{C}$ (lit. ${ }^{8} 222-224{ }^{\circ} \mathrm{C}$ ). $R_{f}=0.75$, pet. ether/EtOAc (3:1). IR (KBr plate): $v_{\max } 3030,1665$ $(\mathrm{C}=\mathrm{O}), 1600,740 \mathrm{~cm}^{-1} . \mathrm{H}^{1}$-NMR $\left(\mathrm{CDCl}_{3}, 200 \mathrm{MHz}\right) \delta: 7.97$ (bs, $\left.1 \mathrm{H}, \mathrm{H}-\beta\right), 7.85\left(\mathrm{dd}, 1 \mathrm{H}, \mathrm{C}_{5}-\mathrm{H}\right)$, 6.85-7.0 (m, 2H, Ar-H), 7.05-7.37(m, 8H, Ar-H), 7.40 (m, 1H, Ar-H), 6.45 (bs, 1H, $\left.\mathrm{C}_{2}-\mathrm{H}\right)$; MS 
(m/z, \%): $380\left(\mathrm{M}^{+}, 49\right), 345\left(\mathrm{M}^{+}-\mathrm{Cl}, 9\right), 269\left(\mathrm{M}^{+}-\mathrm{C}_{6} \mathrm{H}_{4} \mathrm{Cl}, 10\right), 241$ (12), 225 (50), 199 (8), 189 (34), 149 (10), 121 (100).

(E)-3-(4-Bromobenzylidene)-2-(4-bromophenyl)chroman-4-one (3b). Colorless solid, mp 243-245 ${ }^{\circ} \mathrm{C}$ (lit. $\left.{ }^{30} 245{ }^{\circ} \mathrm{C}\right) . R_{f}=0.76$, pet. ether/EtOAc (3:1). IR (KBr plate): $v_{\max } 3040,1670$ $(\mathrm{C}=\mathrm{O}), 1610,810,750,650 \mathrm{~cm}^{-1} . \mathrm{H}^{1}-\mathrm{NMR}\left(\mathrm{CDCl}_{3}, 200 \mathrm{MHz}\right) \delta: 7.96$ (bs, $\left.1 \mathrm{H}, \mathrm{H}-\beta\right), 7.83$ (dd, $\left.1 \mathrm{H}, \mathrm{C}_{5}-\mathrm{H}\right), 6.85-7.09$, (m, 2H, Ar-H), 7.11-7.44 (m, 8H, Ar-H), 7.46 (m, 1H, Ar-H), 6.43 (bs, $\left.1 \mathrm{H}, \mathrm{C}_{2}-\mathrm{H}\right)$.

(E)-3-(p-Methylbenzylidene)-2-p-tolylchroman-4-one (3c). Colorless solid, mp $124{ }^{\circ} \mathrm{C}$ (lit. $^{34}$ 126-127 $\left.{ }^{\circ} \mathrm{C}\right) . R_{f}=0.74$, pet. ether/EtOAc (3:1). IR (KBr plate): $v_{\max } 2960,2870,1675(\mathrm{C}=\mathrm{O})$, 1620, 1600, 810, 770, $750 \mathrm{~cm}^{-1} . \mathrm{H}^{1}$-NMR $\left(\mathrm{CDCl}_{3}, 200 \mathrm{MHz}\right) \delta: 8.05$ (bs, $\left.1 \mathrm{H}, \mathrm{H}-\beta\right), 7.88(\mathrm{dd}, 1 \mathrm{H}$, $\left.\mathrm{C}_{5}-\mathrm{H}\right), 6.87-7.02(\mathrm{~m}, 2 \mathrm{H}, \mathrm{Ar}-\mathrm{H}), 7.09-7.30$ (m, 8H), 7.41 (m, 1H, Ar-H), 6.61 (bs, 1H, $\left.\mathrm{C}_{2}-\mathrm{H}\right)$, $2.34(\mathrm{~s}, 3 \mathrm{H}), 2.28(\mathrm{~s}, 3 \mathrm{H})$.

2-(2,3,4-Trimethoxyphenyl)-4H-chromen-4-one (4). Colorless solid, mp $175{ }^{\circ} \mathrm{C}\left(\right.$ lit. $\left.^{22} 174{ }^{\circ} \mathrm{C}\right)$; $R_{f}=0.35$, pet. ether/EtOAc (3:1). IR (KBr plate) $v_{\max } 3066,2990,1649(\mathrm{C}=\mathrm{O}), 1600,1463$, 1120, 1002, $756 \mathrm{~cm}^{-1} . \mathrm{H}^{1}-\mathrm{NMR}\left(\mathrm{CDCl}_{3}, 200 \mathrm{MHz}\right) \delta$ : $8.22\left(\mathrm{~d}, J 8.7 \mathrm{~Hz}, 1 \mathrm{H}, \mathrm{C}_{5}-\mathrm{H}\right), 7.42-7.76$ (m, 3H, Ar-H), 7.15 (s, 2H, C2'-H, C6'-H ), 6.78 (s, 1H, H-3), 3.97 (s, 6H), 3.94 (s, 3H). MS (m/z, \%): $312\left(\mathrm{M}^{+}, 64\right), 297$ (100), 269 (69), 254 (18), 238 (28), 182 (34), 142 (59).

General procedure for the synthesis of O-heterocycles 6, 8-10. To a cold solution of $o$ hydroxycarbonyl compound $\mathbf{1 a - d}(5 \mathrm{mmol})$ and malononitrile / cyanoacetamide $\mathbf{5 a , b}(5 \mathrm{mmol})$ in absolute ethanol $(20 \mathrm{~mL})$ was added dropwise $\mathrm{SiCl}_{4}(20 \mathrm{mmol})$ and the mixture was allowed to stir for the recorded time. Then, the mixture was poured into ice-water $(100 \mathrm{~mL})$, the formed ppt was filtered, dried and recrystallized from ethanol or acetone to give pure coumarins $\mathbf{6}^{18,31}$ The same procedure was applied to synthesize the dibenzospiropyrans 8-10 through the reaction of salicylaldehyde with cycloalkanones / diphenylacetone 7a-f in the presence of $\mathrm{SiCl}_{4}$ in ratio 1:1:3, respectively. The dibenzospirans 8a-d, ${ }^{32,35} \mathbf{9}^{33} \mathbf{1 0}^{33}$ are known compounds and all physical data were in agreement with literature while compound $\mathbf{8 e}$ is unknown. Data for some representative examples are listed below.

7,8-Dihydro-6H-chromeno[3,2-d]xanthene (8b). Colorless crystals, mp $156{ }^{\circ} \mathrm{C}\left(\right.$ lit. $\left.{ }^{32} 156{ }^{\circ} \mathrm{C}\right)$. Recrystallization from ethanol. $R_{f}=0.72$, pet. ether/EtOAc (3:1). IR (KBr plate): $v_{\max } 3040$, 2825, 1610, 1600, 1580, 1480, 1370, 1220, 1126, 1029, 960, $756 \mathrm{~cm}^{-1} .{ }^{1} \mathrm{H}-\mathrm{NMR}\left(\mathrm{CDCl}_{3}, 200\right.$ MHz) $\delta: 7.27-7.12(\mathrm{~m}, 4 \mathrm{H}, \mathrm{Ar}-\mathrm{H}), 7.01(\mathrm{t}, J 7 \mathrm{~Hz}, 2 \mathrm{H}, \mathrm{Ar}-\mathrm{H}), 6.83$ (d, J $7 \mathrm{~Hz}, 2 \mathrm{H}, \mathrm{Ar}-\mathrm{H}), 6.69$ (s, $2 \mathrm{H},=\mathrm{CH}), 2.70-2.45(\mathrm{t}, J 9 \mathrm{~Hz}, 4 \mathrm{H}), 1.95-1.72(\mathrm{~m}, 2 \mathrm{H})$; MS $(m / z, \%): 289\left(\mathrm{M}^{+}+1,97\right), 288\left(\mathrm{M}^{+}\right.$, 98), 287( $\left.\mathrm{M}^{+}-1,100\right), 271\left(\mathrm{M}^{+}-\mathrm{OH}, 97\right), 260$ (24), 181 (59).

3,3'-Tetramethylene dibenzospiropyran (8d). Pale yellow solid, mp 202-204 ${ }^{\circ} \mathrm{C}$ (lit. ${ }^{35}$ 207-208 ${ }^{\circ} \mathrm{C}$ ). Recrystallization from acetone. $R_{f}=0.72$, pet. ether/EtOAc (3:1). IR (KBr plate): $v_{\max } 3062$, 2918, 2850, 1648, 1607, 1575, 1484, 1456, 1376, 1227, 1123, 1080, 976, 927, 906, $757 \mathrm{~cm}^{-1} .{ }^{1} \mathrm{H}-$ NMR $\left(\mathrm{CDCl}_{3}, 300 \mathrm{MHz}\right) \delta: 7.12(\mathrm{~m}, 4 \mathrm{H}, \mathrm{Ar}-\mathrm{H}), 6.95$ (t, J 7.5 Hz, 2H, Ar-H), 6.79 (d, J 7.5 Hz, $2 \mathrm{H}, \mathrm{Ar}-\mathrm{H}), 6.65(\mathrm{~s}, 2 \mathrm{H},=\mathrm{CH}), 2.56(\mathrm{dd}, J 13.1,5.1 \mathrm{~Hz}, 2 \mathrm{H}), 2.40(\mathrm{t}, J 12.6 \mathrm{~Hz}, 2 \mathrm{H}), 2.04(\mathrm{~m}$, 2H), $1.52(\mathrm{t}, J 9.9 \mathrm{~Hz}, 2 \mathrm{H}) .{ }^{13} \mathrm{C}-\mathrm{NMR}\left(\mathrm{CDCl}_{3}, 75 \mathrm{MHz}\right) \delta: 149.8,135.4,128.8,126.1,123.6$, 
121.7, 120.9, 116.3, 100.7, 33.5, 32.2; Anal. Calcd for $\mathrm{C}_{21} \mathrm{H}_{18} \mathrm{O}_{2}$ : C, 83.42; H, 6.00\%; Found: C, 83.19; H, 5.92\%.

3,3'-Pentamethylene dibenzospiropyran (8e). Pale yellow solid, mp $187^{\circ} \mathrm{C}$; Recrystallization from acetone. $R_{f}=0.8$, pet. ether/EtOAc (3:1). IR (KBr plate): $v_{\max } 3070,2923,2855,1574$, $1483,1451,1320,1227,1125,1064,946,880,749 \mathrm{~cm}^{-1} .{ }^{1} \mathrm{H}-\mathrm{NMR}\left(\mathrm{CDCl}_{3}, 400 \mathrm{MHz}\right) \delta: 7.07-$ 7.13 (m, 4H, Ar-H), 6.89-6.94 (t, J 7.6 Hz, 2H, Ar-H), 6.81-6.83 (d, J 8 Hz, 2H, Ar-H), 6.56 (s, $2 \mathrm{H},=\mathrm{CH}), 2.4(\mathrm{~m}, 4 \mathrm{H}), 1.8(\mathrm{~m}, 2 \mathrm{H}), 1.5(\mathrm{~m}, 4 \mathrm{H}) .{ }^{13} \mathrm{C}-\mathrm{NMR}\left(\mathrm{CDCl}_{3}, 100 \mathrm{MHz}\right) \delta: 149.9,134.0$, 128.7, 126.0, 123.1, 121.4, 119.7, 115.7, 101.8, 32.4, 27.5, 26.5; Anal. Calcd for $\mathrm{C}_{22} \mathrm{H}_{20} \mathrm{O}_{2}$ : C, 83.51; H, 6.37\%; Found: C, 83.63; H, 6.21\%.

\section{References}

1. For the synthesis and biological activities of 3-benzylideneflavanone derivatives, see: (a) Foroumadi, A.; Samzadeh-Kermani, A.; Emami, S.; Dehghan, G.; Sorkhi, M.; Arabsorkhi, F.; Heidari, M. R.; Abdollahi, M.; Shafiee, A. Bioorg. Med. Chem. Lett. 2007, 17, 6764. (b) Rajan, Y. C.; Kanakam, C. C.; Selvam, S. P.; Murugesan, K. Tetrahedron Lett. 2007, 48, 8562 and further references cited therein. (c) Basavaiah, D.; Bakthadoss, M.; Pandiaraju, S. Chem. Commun. 1998, 1639. (d) Rajan, Y. C.; Kanakam, C. C. Tetrahedron Lett. 2008, 49, 3023. (e) Das, B.; Chowdhury, N.; Damodar, K.; Banerjee, J. Chem. Pharm. Bull. 2007, 55, 1274.

2. (a) Subramaniyan, G.; Raghunathan, R.; Martin Castro, A. M. Synthesis 2002, 2440. (b) Subramaniyan, G.; Raghunathan, R.; Nethaji, M. Tetrahedron 2002, 58, 9075. (c) Jayashankaran, J.; Manian, R. D. R. S.; Raghunathan, R. Lett. Org. Chem. 2006, 3, 917.

3. (a) Kim, S. H.; Kim, S. H.; Kim, J. N. Bull. Korean Chem. Soc. 2008, 29, 2039. (b) Dong, X.; Liu, T.; Gao, Y.; Chen, J.; Hu, Y. Synth. Commun. 2009, 39, 3722.

4. (a) Joseph, L.; George, M.; Gopal, N. Highland Med. Res. J. 2007, 5, 20. (b) Joseph, L.; George, M.; Kassaye, G. Afr. J. Cln. Exper. Microbiol. 2008, 9, 147. (c) Joseph, L.; George, M. J. Basic Appl. Sci. 2010, 6, 135.

5. For a review, see: Levai, A. Arkivoc 2004, (vii), 15-33 and references cited therein.

6. (a) Patel, J. M.; Soman, S. S. J. Heterocycl. Chem. 2009, 45, 1729. (b) Adams, J. H. J. Org. Chem. 1967, 32, 3992. (c) Szell, T.; Unyi, R. E .M. J. Org. Chem. 1963, 28, 1146. (d) Seikel, M. K.; Lounsbury, M. J.; Wang, S.-C. J. Org. Chem. 1962, 27, 2952.

7. (a) Chawla, H. M.; Sharma, S. K. Heterocycles 1987, 26, 1527. (b) Chawla, H. M.; Sharma, S. K. Indian J. Chem. 1987, 26B, 1075. (c) Chawla, H. M.; Sharma, S. K. J. Chem. Res (S). 1988, 96.

8. Dhara, M. G.; Mallik, U. K.; Mallik, A. K. Indian J. Chem. 1996, 35B, 1214.

9. Kendall, J. D.; Axford, A. J. Brit. Patent 672741 1952; Chem. Abstr. 1955, 49, 84g.

10. Bonsignore, L.; Cottiglia, F., Elkhaili, H.; Jehl, F.; Lavagna, S. M.; Loy, G.; Manna, F.; Monteil, H.; Pompei, D.; Secci, D. Farmaco 1998, 53, 425. 
11. Bonsignore, L.; De Logu, A.; Loy, G.; Lavagna, S. M.; Secci, D. Eur. J. Med. Chem. 1994, $29,479$.

12. Jonsson, D.; Erlandsson, M.; Unden, A. Tetrahedron Lett. 2001, 42, 6953.

13. Doucet, C.; Pochet, L.; Thierry, N.; Pirotte, B.; Delarge, J.; Reboud-Ravaux, M. J. Med. Chem. 1999, 42, 4161.

14. Pochet, L.; Doucet, C.; Schynts, M.; Thierry, N.; Boggetto, N.; Pirotte, P.; Jiang, K. Y.; Masereel, B.; de Tullio, P.; Delarge, J.; Reboud-Ravaux, M. J. Med. Chem. 1996, 39, 2579.

15. (a) Junek, H. Monatsh. Chem. 1963, 94, 192. (b) Ziegler, E.; Junek, H. Monatsh. Chem. 1955, 86, 29. (c) Baker, W.; Howes, C. S. J. Chem. Soc. 1953, 119. (d) Sastry, V. D. N.; Seshadri, T. R. Proc. Ind. Acad. Sci. 1942, 16A, 29. (e) Costa, M.; Areias, F.; Abrunhosa, L.; Venancio, A.; Proenca, F. J. Org. Chem. 2008, 73, 1954 and references cited therein.

16. Valizadeh, H.; Mahmoodian, M.; Gholipour, H. J. Heterocycl. Chem. 2011, 48, 799.

17. Moussaoui, Y.; Ben Salem, R. C. R. Chimie 2007, 10, 1162.

18. Zhang, M.; Zhang, A.-Q. Synth. Commun. 2004, 34, 4531.

19. (a) Salama, T. A.; Novak, Z. Tetrahedron Lett. 2011, 52, 4026. (b) Salama, T. A.; Elmorsy, S. S.; Khalil, A. M.; Ismail, M. A. Chem. Lett. 2011, 40, 1149. (c) Salama, T. A.; Elmorsy, S. S. Chin. Chem. Lett. 2011, 22, 1171. (d) Salama, T. A.; El-Ahl, A. S.; Elmorsy, S. S.; Khalil, A. M.; Ismail, M. A. Tetrahedron Lett. 2009, 50, 5933. (e) Salama, T. A.; Elmorsy, S. S.; Khalil, A. M.; Ismail, M. A. Tetrahedron Lett. 2007, 48, 6199. (f) Salama, T. A.; Elmorsy, S. S.; Khalil, A. M. Tetrahedron Lett. 2007, 48, 4395. (g) Salama, T. A.; Elmorsy, S. S.; Khalil, A. M.; Girges, M. M.; El-Ahl, A. S. Synth. Commun. 2007, 37, 1313. (h) Salama, T. A.; ElAhl, A. S.; Khalil, A. M.; Girges, M. M.; Lackner, B.; Steindl, C.; Elmorsy, S. S. Monatsh. Chem. 2003, 134, 1241.

20. (a) Al-Hourani, B. J.; Sharma, S. K.; Suresh, M.; Wuest, F. Bioorg. Med. Chem. Lett. 2012, 22, 2235. (b) Shimoda, Y.; Kotani, S.; Sugiura, M.; Nakajima, M. Chem. Eur. J. 2011, 17, 7992. (c) Rossi, S.; Benaglia, M.; Genoni, A.; Benincori, T.; Celentano, G. Tetrahedron 2011, 67, 158. (d) Kashiwagi, T.; Kotani, S.; Sugiura, M.; Nakajima, M. Tetrahedron 2011, 67, 531. (e) Khatab, T. K.; El-Bayouki, K. A. M.; Basyouni, W. M. Tetrahedron Lett. 2011, 52, 1448. (f) Azizi, N.; Baghi, R.; Ghafuri, H.; Bolourtchian, M.; Hashemi, M. Synlett 2010, 379.

21. (a) Keane, D. D.; Marathe, K. G.; O’Sullivan, W. I.; Philbin, E. M.; Simons, R. M.; Teague, P. C. J. Org. Chem. 1970, 35, 2286. (b) Sternhell, S. Rev. Pure Appl. Chem. 1964, 14, 15.

22. Reichel, L.; Henning, H. G. Liebigs Ann. Chem. 1959, 621, 72.

23. (a) Ahmed, S.; Wagner, H.; Razaq, S. Tetrahedron 1978, 34, 1593. (b) Mallik, U. K.; Saha, M. M.; Mallik, A. K. Indian J. Chem. 1989, 28B, 970.

24. Rho, J. S.; Cho, H. Y.; Hong, S. S.; Cho, T. W. Korean Patent, 127 (1993); Chem. Abstr. 1994, 120, 259913r.

25. (a) Kotha, S.; Chakraborty, K.; Brahmachary, E. Synlett 1999, 1621. (b) Elmorsy, S. S.; Khalil, A. M.; Girges, M. M.; Salama, T. A. Tetrahedron Lett. 1997, 38, 1071. (c) Elmorsy. S. S.; Khalil, A. M.; Girges, M. M.; Salama, T. A. J. Chem. Res. (S) 1997, 232. 
26. Elmorsy, S. S.; El-Ahl, A. S.; Motty, F. M.; Amer, F. A. Egypt J. Chem. 1997, 40, 139.

27. (a) Francke, W.; Kitching, W. Curr. Org. Chem. 2001, 5, 233. (b) Yokoyama, A.; Goto, Y.; Mizushina, Y.; Sakaguchi, K.; Hayashi, H. Biochemistry 2000, 39, 5995.

28. Aho, J. E.; Pihko, P. M.; Rissa, T. K. Chem. Rev. 2005, 105, 4406.

29. Ardes-Guisot, N.; Ouled-Lahoucine, B.; Canet, I.; Sinibaldi, M. E. Tetrahedron Lett. 2007, $48,8511$.

30. Ryan, H.; Callaghan, G. C. Proc. Roy. Irish Acad. 1929, 39B, 124; Chem. Abstr. 1930, 24, 4037.

31. (a) Aly, F. M.; Bedair, A. H.; Selim, M. R. Afinidad 1987, 489. (b) Inukai, Y.; Mose, K. Jap. Patent, 87 1366, 1966; Chem. Abstr. 1967, 67, 63999m. (c) Srinivas, K.; Krishna, K. L.; Sivaprasad, A.; Rao, P. S. Ind. J. Chem. 1998, 37B, 936.

32. Borsche, W.; Geyer, A. Liebigs Ann. Chem. 1912, 393, 29.

33. Dickinson, R.; Heilbron, I. M.; O'Brien, F. J. Chem. Soc. 1928, 2077.

34. Vydzhak, R. N.; Panchishin, S. Ya. Russ. J. Gen. Chem. 2008, 78, 2391.

35. Xin, Y.; Jiang, H.; Zhao, J.; Zhu, S. Tetrahedron 2008, 64, 9315. 